\title{
Investigating the Use of Interactive Whiteboard Technology in the English Language Classroom through the Lens of a Critical Theory of Technology
}

\author{
E. Cutrim Schmid* \\ University of Education Heidelberg, Germany
}

Several authors have pointed out that CALL research does not have the academic status that it should have because it does not take place within a well-developed theoretical framework. For this reason, there have been several proposals which seek to anchor CALL research within various existing theoretical frameworks-for instance, instructed second language acquisition and sociocultural theory. This article aims at contributing to the theoretical and methodological development of CALL research by throwing light on the potential benefits of using a particular conceptual framework - that of a critical theory of technology, which stresses the necessity of contextualizing technology and understanding its social embeddeness when investigating its integration in any context. The data discussed here are drawn from a qualitative study, carried out as part of a Ph.D. research programme, which aimed at exploiting the potential of Promethean interactive whiteboard technology for the teaching of English as a foreign language. The findings indicate that the final picture of technology use in the context investigated was seen as the result of the interaction of several elements, such as: the inherent characteristics of the technology, teacher's pedagogical beliefs, students' own understandings of the potentials of the technology and the negotiations between students and the teacher regarding how the technology should be pedagogically exploited.

\section{Introduction}

This article reports on a qualitative study concerning the use of interactive whiteboard (IWB) technology in the teaching of English for academic purposes/study skills to

*Corresponding author. English Department, University of Education (Pädagogische Hochschule), Keplerstraße 87, D-69120, Heidelberg, Germany. Email: euline.cutrim.schmid@ph-heidelberg.de 
international students. The study was carried out at the University of Lancaster (UK), as part of a Ph.D. research programme, in the summers of 2003 and 2004. It drew on a critical theory of technology perspective (Feenberg, 1991) to analyze the impact of interactive whiteboard (IWB) technology in the language classroom investigated.

The IWB is a touch-sensitive electronic presentation device. Fully-functioning interactive whiteboards usually comprise four components: a computer, a projector, appropriate software and the display panel, which is a large free-standing or wall mounted screen up to 2 metres by 1 metre in size. Figure 1 illustrates how this technology works.

The Promethean TM system (the brand of IWB used in this research), uses electromagnetic sensing technology with an electronic pen. The company has also developed a whole suite of software and peripheral hardware to complement the use of an interactive whiteboard, such as 'ACTIVstudio' software and the 'ACTIVslate' and 'ACTIVote' systems. ${ }^{2}$

Drawing from research on the educational use of IWB technology (see Bell, 2000; Burden, 2002; Glover \& Miller, 2001; Goodison, 2003; Greiffenhagen, 2000; Levy, 2002; Walker, 2003), the researcher identified some features of the IWB technology that appeared particularly promising for experimentation and investigation in the EAP/study skills context in question. This led to the decision of focusing on the potential of the technology for implementing a hands-on approach ${ }^{3}$ to learning about English academic literacy practices, based on whole-class interaction and collaborative learning.

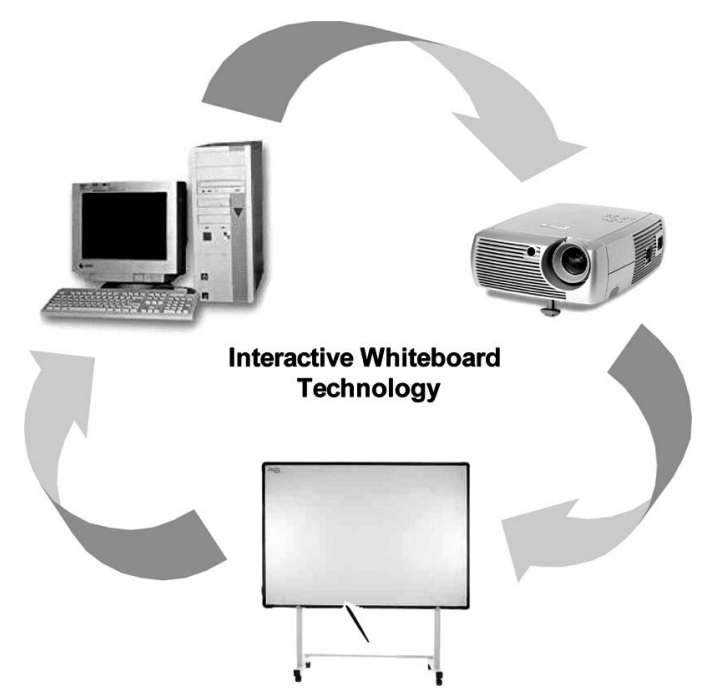

Figure 1. How IWB technology works. The computer images are displayed on the board by the digital projector. The images then can be seen and all applications on the computer can be controlled via touching the board, either with your finger, or with an electronic pen/stylus 
The IWB technology was then intensively used in two complementary courses of the Lancaster EAP/study skills programme with a view to exploring its potential in terms of these main pedagogical zones. ${ }^{4}$ The research project had two main stages (referred to henceforth as Study 1 and Study 2). In the first stage (2003), the IWB technology was investigated in lessons that aimed at educating students to have control over online tools and resources, which can be used for language learning and academic purposes, and to be critical users of the Web and the Internet. In the second stage (2004), the focus was on the effects of using the IWB technology in lessons that contained a more directly language development-oriented focus and that at the same time fostered students' awareness of ICT learning resources.

Most students who took part in the research tended to be from mainland China and Taiwan, and their target subject area was mainly management sciences. However, there were also students from Japan, Korea, Africa, Saudi Arabia, South America and Europe. Twenty-nine and thirty-one students were involved in Study 1 and Study 2, respectively. The students had, in general, a good command of the English language. In order to be accepted on the programme they needed to have achieved an IELTS score of at least 6.0 (postgraduates) or 5.5 (undergraduates). All the students in both studies were postgraduates, apart from one undergraduate in Course 1, and their ages ranged from 20- to 36-years.

The study can be seen as a form of classroom-based research in which the researcher undertook the dual roles of teacher and researcher. A total of 24 lessons (each lasting 90 minutes) were developed, taught and investigated. In order to address the purposes of such a study, two main research questions were formulated:

1. What kinds of interactions are produced when the technology is implemented?

2. What kinds of pedagogical goals (for example, to enhance collaboration) may the technology help to achieve?

Apart from addressing pedagogical aspects, the research was also aimed at making theoretical and methodological contributions at a broader level-that is, to the development of CALL research and practice in general. Thus, in order to do so, another research question was formulated to guide the study: How can a 'critical theory of technology' be used to shed light on the process of IWB technology integration in the microcosm of the language classroom? It is to help answer this question that this article has been written.

\section{Critical Theory of Technology}

A critical theory of technology considers that each piece of technology is constructed by the interaction between its design and how it is appropriated by its users. From this perspective, the final picture of technology use is seen as the result of the interaction of several elements, such as: the inherent characteristics of the technology, teacher's pedagogical beliefs and the kind of pedagogical activities that were designed as a result of them, students' own understandings of the potentials of the technology and 
the negotiations between students and the teacher regarding how the technology should be pedagogically exploited.

Although the critical theory of technology has already been used by other researchers in the field of CALL, their focus was mainly on the analysis of processes of technology integration in a broader sense, such as the analysis of the development of electronic literacies in college writing classes across various institutions (Warschauer, 1999) and the analysis of educational technological reform in a specific country (Warschauer, 2003). This article, however, aims at contributing to an understanding of how this theory can be used to shed light on the process of technology integration in the microcosm of the classroom, by analysing how the IWB technology was taken up and transformed by the various members of the classroom community in the context investigated.

The 'critical theory of technology', as put forward by Feenberg (1991), can be contrasted with two other perspectives: 'instrumentalism' and 'determinism'. Feenberg demonstrates the limitations of these more traditional theories of technology, which either characterize technology as neutral, or essentialize technology as some kind of autonomous, deterministic force acting on society.

Thus, as Feenberg (1991) points out, the instrumental theory offers the most widely accepted view of technology. According to this theory, technologies are simply 'tools' standing ready to serve the purposes of their users. Technology is seen as "indifferent to the variety of ends it can be employed to achieve" (Feenberg, 1991, p. 5). In this view, it is not technology per se which creates problems or solutions, but rather the way in which technologies are used.

On the other hand, theories of technological determinism emerged after the Second World War which either celebrated technology's modernizing features or blamed it for the crisis of western civilization. According to Feenberg, theorists such as Heidegger, Ellul and their followers attributed a negative essence to technology, seeing it as a force of domination and totalitarianism. Technological determinism suggests that the technology itself automatically brings about certain results (whether good or bad).

Feenberg (1991) has criticized both of these positions and put forward an alternate view which he calls the critical theory of technology. He argues that 'determinist' and 'instrumentalist' conceptions tend to decontextualize technology, abstract it from social practices, and thus fail to provide understanding of its social and historical embeddedness. For him, both of these approaches underestimate the role of social context in helping shape the impact of technology. He points out that technology is not 'determinist', but is shaped by human agency. At the same time, he argues that people cannot use technology towards any ends they wish, as technology carries with it certain values/biases which reflect its own historical development and design. Therefore, it is also not neutral. Therefore, Feenberg views technology as a 'battlefield' or 'site-of-struggle' where individuals and social groups can struggle to influence and change technological design, uses and meanings. As Warschauer (2003, p. 22) points out, technology is seen not as a "thing in the ordinary sense of the word, but rather an ambivalent process of development suspended between possibilities". 
Since a critical theory of technology regards technology as socially constructed, embodying historically specific social biases and values, it is thus considered impossible to evaluate technology use in a social vacuum. According to this theory, it is particularly important to examine the underlying power relations that shape how technology is designed and used. From this perspective, each piece of technology is 'constructed' by the interaction between its design and how it is appropriated by its users.

More specifically in the field of CALL, Warschauer (1998) points out that earlier investigations on computers in the language classroom tended to reflect a 'determinist' approach. As already pointed out, this is a perspective in which the computer is seen as an all-powerful machine that in and of itself produces certain determined results. Thus research that is based on this approach seeks to understand the overall effect of the computer on the language learning process.

In contrast to this perspective, if technology is investigated simply as a tool, the focus is on allowing the researcher to examine its effects on certain aspects of the learning process, such as: how specific software helps learners to learn new vocabulary or improve their pronunciation. Warschauer (1998) draws attention to the fact that, although this instrumental view appropriately takes the emphasis away from the machine per se, it underestimates the effects that new technologies may have on the language learning environment in a broader sense. From this perspective, "language learning, the teacher and the learner are all seen as unchanged by the introduction of new technologies" (Warschauer, 1998, p. 1).

This 'instrumental' approach tends to typify much CALL-based research. Thus, Chapelle (2003, p. 76) seems to have this kind of research approach in mind when she points out that priority in the field should be the research that is able to "isolate the features of the technology that have helped the students and therefore the results can contribute to the professional knowledge about CALL'. Therefore, for Chapelle, the focus of CALL research should be on the use of technology as a tool for promoting language acquisition processes.

Since the research reported here focused on classroom practices so as to understand the complex process of integration of IWB technology into the pedagogical process, it was felt that the critical theory of technology was the most appropriate theoretical foundation for conducting the investigation. As Bruce (1997, p. 12) points out "in order to understand what technology means, we must examine how it is designed, interpreted, employed, constructed, and reconstructed through value-laden daily practices". Therefore, in order to understand the impact of a new technology on the pedagogical process it is necessary to understand the circumstances in which it is implemented and how it has been interpreted by the participants of this process.

The IWB technology was thus investigated neither as an all-powerful machine (the determinist view), nor as simply a tool for teaching/learning (the instrumental view). Rather, the study took into account the social and pedagogical issues which influenced how the technology was adopted, exploited and transformed by the group by which it was used, the changes the use of the technology helped to create and its effects on pedagogical practices and student learning. 


\section{Research Methodology}

While the deterministic and instrumental research paradigms lend themselves to experimental research methods, a critical theory of technology approach tries to answer questions that can be more effectively addressed by interpretive qualitative research. It therefore seemed reasonable to conclude that such a research approach constituted the most appropriate one for investigating how, in the research site, the technology was appropriated and reconstructed by the group as well as its impact on pedagogical practice, classroom social dynamics and student learning processes.

Warschauer (1999) points out there has so far been insufficient qualitative research on technology-enhanced language learning. This issue is also raised by Debski (2003), whose examination of CALL research papers has shown that qualitative research is not very widespread in the field. He points out that, although the number of experimental studies has been declining, in overall terms CALL emerges as a field where researchers use mostly quantitative research methods and take a nonparticipant position with respect to the research setting.

Several authors have therefore emphasised the need for more qualitative research in the technology enhanced language classroom (see Motteram, 1999; Warschauer, 1999). Motteram (1999) suggests that the paradigm shift towards qualitative research that has occurred in much recent social science research should also be applied more widely in CALL classroom research. He argues that "the way we might develop a true theory of CALL is looking at qualitative research methods in the first instance and including teachers as researchers into our own endeavours to give us a more grounded theory". He argues thus for the integration between research and practice, which is considered necessary for the advancement of CALL as an academic discipline (see also Garrett, 1998).

In order to put such an orientation into practice, research data were collected via a variety of ethnographic research instruments, namely classroom observations and feedback from critical colleagues, teacher's field notes, video recording of classes, an online discussion forum, classroom discussions, semi-structured interviews with students, and pre- and post-course student questionnaires.

The main aim of the study was to obtain an understanding of the processes investigated from the insiders' perspectives-that is, teacher and students. To enhance the credibility of the study the following recommended steps were taken (Erickson, 1986): prolonged engagement (observing the classes through the entire cycle); triangulation of data (comparing data across a variety of sources to seek out and confirm regularities); and dialogue with other researchers (by discussing my analyses with critical colleagues and other researchers in research groups and conferences).

\section{Research Findings and Discussion}

As the data analysis will show, the final picture of IWB technology use in the context investigated was seen as the result of the interaction of several elements, such as: the inherent characteristics of the technology; my own pedagogical beliefs and the kind of 
pedagogical activities that were designed as a result of them; students' own understandings of the potentials of the technology; and the negotiations between students and the teacher regarding how the technology should be pedagogically exploited.

\section{Inherent Characteristics of the Technology X Teacher's and Students' Pedagogical Beliefs}

From the perspective of a critical theory of technology, it is considered that all technologies have inherent characteristics that can facilitate or even encourage the implementation of certain approaches, which does not mean that all of this potential will necessarily be realized. In the case of the IWB technology, for instance, one could argue that because the IWB ACTIVote system only supports multiple choice questions, it could promote the design of pedagogical activities based on behaviouristic approaches to CALL (Warschauer \& Healey, 1998) since the system restricts the kind of answers the students can provide and learners are not encouraged to engage discursively with ideas and arguments.

This was in fact one of the points of conflict between the design of the technology and the teacher's own pedagogical beliefs. When the teacher first started to use the IWB technology in the contexts investigated, she was very cynical about the pedagogical potential of the voting system in particular because she believed that the extensive use of multiple-choice questions in the language classroom could restrict students' use of the target language. However, because of the availability of the technology and mainly because the students had shown special interest in it, she had to work on the 'reconstruction' of this component of IWB technology in order to exploit the technology in a way that would not be totally against her pedagogical values and beliefs. One of the teacher's concerns regarding the pedagogical activities that involved the use of the ACTIVote system was to ensure that, apart from pressing a button and selecting an item, students would also be encouraged to engage discursively with the questions through pair or group discussions.

There also seemed to be a conflict between students' pedagogical beliefs and inherent characteristics of the voting system. For instance, the fact that the ACTIVote system allowed the students to guess the correct answer was cited by several students in the individual interviews as one of the main disadvantages of this technology. In the following extract, for instance, a student discusses this issue and its implications for the learning process:

$\mathrm{T}$ : Can you think of any disadvantages of using the voting system in class? For learning during the sessions?

$\mathrm{S}$ : $\mathrm{Ah}$, yes, the sole disadvantage I see is that it gives you the opportunity to guess, and I think this is not a good thing, we have to be sure of what we are doing.

$\mathrm{T}$ : And then you can guess?

S: Yeah, you can guess, you can choose, I vote $\mathrm{A}, \mathrm{A}, \mathrm{A}$; and in the end you may have nearly $50 \%$.

(Post-course interview with Soul, ${ }^{5}$ Study 2) 
In line 3 , he referred to a strategy that can be used by students when they want to obtain a good overall score through guessing. He also highlighted, in lines $4-5$, that this kind of attitude impedes the learning process since the students 'are not sure of what they are doing'- they do not actively engage with the learning material to construct new knowledge. Another student also referred to this issue and proposed a solution to the problem:

S: I think the voting system can never answer who is right and who is wrong. After the voting system the teacher says, let the students who answered right stand up and explain.

[Laughter]

$\mathrm{T}$ : Why do you think this is important?

S: I speak too much? [All laugh

(Post-course interview with Win/Danny, Study 2)

In line 1 , the student drew attention to a certain limitation of the ACTIVote system in terms of providing an overall picture of students' knowledge and level of understanding of issues taught in the class, since the students are able to guess. Therefore, he proposed, in lines $2-3$, that the students be asked to justify their choices in case they provided the right answers. In line 6 , he argued further that this kind of technique would also benefit those students who were not as successful and needed to accommodate their knowledge.

Therefore, the student emphasised the importance of working towards principled knowledge (Edwards \& Mercer, 1987) - that is, conceptual understanding. In other words, for these students it is important that the teacher focus more on the rationale behind the answers: on the 'whys' and not so much on the voting results or on students' performances.

By taking this limitation of the technology into account, the teacher worked towards a more 'constructivist' use of the system. One of the results of such approach was that in the context investigated, the voting activities involved a great amount of peer discussions, which is related to her attempt to 'redesign' this component of IWB technology to a certain extent, and ensure that, apart from pressing a button and selecting an item, students would also be encouraged to engage discursively with the questions through pair or group discussions. Therefore, in some activities the students were encouraged to explain the rationale for their answers before submitting their responses. In others they had to vote in small groups and thus had to get to an agreement as to what would be the correct answer. 
However, although the teacher (and students) managed to 'redesign' the technology to a certain extent in favour of a more learner-centred and discursive pedagogical approach, the 'original' design of the technology contains features that limited the possibilities for pedagogical exploitation of the technology in this regard. Therefore, the main point I want to bring up here is that, although the technology can be seen as a "medium in which a variety of methods, approaches, and pedagogical philosophies may be implemented" (Garrett, 1998, p. 75), its inherent characteristics also play an important role in limiting or extending the possibilities of 'reconstruction' in favour of one or another pedagogical approach, a view very much in keeping, of course, with a critical theory of technology perspective.

\section{Teachers' Preconceptions and Students' Expectations}

Research findings also indicate that the process of technology 'reconstruction' involved conflicts and negotiation between teacher and learners and among learners themselves. As it will be shown, the IWB technology was appropriated by the teacher and the learners in different ways regarding certain aspects of technology use. For instance, regarding students' own use of the technology for self-expression.

The data indicate that the students recognized the potential of the technology for raising their motivation for sharing knowledge with their course mates by means of individual and group presentations. In Study 1, the students were given plenty of opportunities to use the whiteboard for this purpose. In Study 2, however, they had fewer chances to make use of IWB technology for self-expression. As a result, several students in Study 2 expressed their dissatisfaction with the fact that they were not encouraged to use IWB technology tools to express themselves creatively through a variety of media. This happened because Study 2 was designed to have a more directly language oriented focus than Study 1. Therefore, the teacher drew upon the teaching methods that she had been using as a language teacher for the past ten years. In the teacher's previous teaching experience, the use of the traditional whiteboard was minimized in favour of other more 'learner centred' activities such as: pair and group work. Therefore, the traditional whiteboard was mainly used by the teacher for presentation, demonstration and modelling; and when the students performed their own presentations they tended to do it from their desks. The students, however, interpreted the technology in a fundamentally different way.

When some students were inquired about why they thought it would be important to use the board more often, since in other language lessons they hardly ever used the whiteboard, two of them provided the following responses:

It's a new machine, new for us, so we want to know, it's like a computer ... we have a new computer, we want to learn how to use it, because it's new, it's a new machine. (Post-course interview with Lauren, Study 2)

I use the whiteboard I have the impression that I am using my home computer, and accessing the websites, but it's very large, you see, it's not a very tiny screen, it's a large screen. (Post-course interview with Soul, Study 2) 
The data seem to indicate that the students saw the interactive whiteboard much more as a computer than as a whiteboard. This would explain their increased interest in using the board for presentation, since in language lessons in which IWB technology is not used this is not usually the case. In fact, convincing students to perform certain tasks at the board is often a challenge for language teachers due to traditional conceptions of teacher-learner roles (cf. Shamim, 1996).

In the final section of the interviews in Study 2, the teacher-researcher asked the students to enumerate some suggestions or a recommendation they would give to a friend who was going to use IWB for the first time in a language lesson. The great majority of the students ( 8 out of 10 ) replied that they would suggest that the friend take every opportunity to use the whiteboard him/herself. As it can be seen in the extract below:

S: Get a chance, if you have a chance to go to the front and use the machine, it's very

interesting to use it, there won't be a chance for everyone to go to the front.

T: So, do you like going to the front? Do you think it's a good thing to go to the front and use that?

S: Yeah.

T: Would you like to write on the board, do you think as a student ... during the sessions, would you have liked to have more opportunities to go the board?

S: $\quad$ Sure, but I can't tell him that we don't have the time, but if we have a chance to write the word and to see our handwriting become typed, oh, that will be interesting!

(Post-course interview with Sheena, Study 2)

The students seemed to be interested in using the electronic whiteboard not only because they wanted to express their new knowledge but also or mainly because they would be doing that through a medium that they found exciting and interesting. However, as the data indicate, the students could not always make use of the technology in the ways they had envisioned because of the power relations that characterize the classroom context (Edwards \& Mercer, 1987). Students' own use of the technology also depended on how the technology was being reconstructed by the teacher's pedagogical beliefs, goals and values.

The data thus indicate that there was a point of conflict between the teacher and learners regarding students' use of technology for self-expression. While the teacher was still following the model of the 'traditional' language classroom and wanted to restrict students' use of the electronic whiteboard in favour of more learner-centred activities, such as group and pair work activities, students expressed their favour for lessons in which they would move back and forth from the interactive whiteboard to their desks, and use the whiteboard to share their knowledge with the whole group or to play the teacher's role. In other words, while the teacher was trying to incorporate the IWB technology into what she understood of a language 
classroom, the students recognized the potential of the technology to go beyond that-that is, to transform it.

\section{Students' Expectations $\times$ Other Students' Expectations}

The data also indicate that the technology was not taken up by all students in the same way. For instance, in the case of the voting system, the data have indicated that the students differed in their views of the advantages of this technology, depending on their personality types, learning styles, knowledge level and so on. While some students wanted to use the technology to hide and deal with their difficulties individually, other students preferred to use the technology to create a sense of community in the classroom, in which they would be able to work on their difficulties with the help of the group.

Research findings indicate that the students liked the element of competition that is encouraged by the ACTIVote system but they wanted to avoid any situations that could lead them to embarrassment or even loss of face in the classroom. Most students preferred to deal with their failures individually, and the use of the ACTIVote system helped them to do so.

In this investigation, although the classes were small, composed of just 9-11 students, all the students preferred to work with the ACTIVote system in anonymous mode. ${ }^{6}$ According to one of the students:

You know your position, you can compete with others but you don't like other people knowing that you got it wrong. (Focus group discussion - 22 September, 2003 - Study 1)

At the interviews most students said that they did not like it when others knew their individual results during the voting sessions. According to these students, this limited the degree of anonymity that the system is able to provide. As discussed earlier, one of the main advantages of the ACTIVote system mentioned by the students was the fact that the use of this technology enabled them to participate more actively and evaluate themselves without the fear of losing face. However, there were some situations in which their individual results were revealed, which created some degree of anxiety among the students.

Although there was some degree of anonymity in all voting activities, some students considered that their individual numbers should have been more 'protected', so that their classmates would not know when they made mistakes or scored poorly in the activities. As the following interview response reveals:

The results, the results of voting system ... if the results is just about the percentage, it will be better, and we can check the individual results, the individual answers, maybe after class, not in a public place, or we can just know that by ourselves. (Post-course interview with Sharon, Study 2)

This student suggests that only the overall scores are presented without emphasis on individual performances. Here she drew attention to the importance of 
establishing clear boundaries between the 'public' and the 'private' in the classroom situation.

Another student regarded the technology as being 'dangerous' because of its power of revealing students' knowledge level, opinions and attitudes:

T: When you saw the results and I showed the overall results, sometimes

I showed the individual results, how did you feel when I showed the results?

S: I think that was a bit anxious. This can be dangerous, this technology can be dangerous, because this is an exhibition of the knowledge of the people.

$\mathrm{T}$ : Ah, you mean privacy intrusion, because you are intruding into peoples' privacy?

S: It depends on the people, because there are people who lead very private lives.

T: I see, they don't want others to see how they are progressing, so it can be dangerous?

(Post-course interview with Lauren, Study 2)

For this student, the ACTIVote system can be used as a tool for 'intruding into people's private lives' with the promise of anonymity. However, when the anonymity is broken - that is, when the students find out each other's numbersthis can become dangerous because some students may not be ready for or willing to expose their weaknesses or even points of view to the whole group. As she stated in line 8, "there are people who lead very private lives". Other students described the way they felt when their individual performances were revealed to the whole group.

Sometimes I feel bad because other people know what I answered and this answer is wrong. (Post-course interview with Miriam, Study 2)

The exercise that, it's not the exercise, but part of the exercise, in the voting exercise, after you vote, you have the results, but you have the number, the number of the answer, but people, I'm afraid people will know that I made a mistake, that I was wrong. If you want to say a disadvantage, that I can tell, that part I like least. (Post-course interview with Sharon, Study 2)

Therefore, the data suggest that some students resented the fact that they had their performances exposed to the whole group through the use of the ACTIVote system.

Other students, however, did not seem to place so much importance on the anonymity aspect of the voting activities. For these students, the friendly atmosphere that prevailed among the students made them feel safer to expose their weaknesses, and flaws to their classmates. As one of the students pointed out: 
T: Because the others, although it's anonymous, sometimes the others can see your number when you are voting, so when I show the results people can see how much you got. Do you care?

S: No, I don't care.

T: No? If the others see?

S: I think in this course the classmates are quite friendly, you know, we can laugh at each other, you make a mistake, how come? Or something like that.

(Post-course interview with Birdie, Study 2)

Another student pointed out an advantage of breaking anonymity:

$\mathrm{T}$ : And do you like the fact that it was anonymous, the names were not shown there?

S: I think I like that. [laughing], if only I know that it's me.

T: Do you like when the others know that you didn't do so well?

S: I don't mind.

T: Because ...

S: Because the voting is informal.

$\mathrm{T}$ : And you think the group ...

S: The group can help me if I did mistakes, they can share with me, what I did, how I performed ... I feel like that.

(Post-course interview with Andy)

In line 3, the student acknowledged that he enjoyed when the voting activity is carried out in anonymous mode. However, he also pointed out, in lines 9-10, that more learning opportunities can be created when the students share their mistakes with each other. By knowing their classmates' difficulties, they would be in a better position to help each other.

Therefore, from the perspective of a critical theory of technology, it can be argued that the technology was not taken up by all students in the same way. While some students wanted to use the technology to hide and deal with their difficulties individually, other students preferred to use the technology to create a sense of community in the classroom, in which they would be able to work on their difficulties with the help of the group. Therefore, the data seem to indicate that the voting system was 'reconstructed' differently by these two groups of students, since they could see their learning processes being supported by the same technology in contrasting ways.

\section{Summary and Conclusion}

The IWB technology was thus investigated not simply as a tool for teaching/learning. A special emphasis was placed on attempting to uncover the social and pedagogical issues which influenced the way in which the technology was taken up by the group. Elements such as technology design, teacher's and students' pedagogical beliefs and values, conflicts and negotiations between teachers and students were taken into 
account in the analysis of the process of IWB technology integration in the context investigated. The idea has been to provide a more complete picture of how the technology was interpreted, taken up and transformed by the group. The technology was thus viewed as a site of struggle and its process of integration was analysed as a complex social process involving restructuring of plans, the development of different social relationships and negotiations of power.

The main advantage of having adopted a critical theory of technology perspective of this kind is that the resulting analysis is more comprehensive, since it accounts for elements that would be unseen in an efficacy- or instrumental-oriented analysis. Within a critical theory of technology perspective, the interpretation of results becomes clearer because not only the effects of the use of the technology on pedagogical practices are analysed, but also the related social cultural and pedagogical elements that created the conditions for that to happen. This way, in my view, it becomes easier to grasp a full understanding of the process of technology integration and to make judgements about the applicability of the findings to other contexts. It is hoped that this illustration of the application of a critical theory of technology conceptual framework will be useful in guiding future research efforts in the field of CALL.

Another important contribution of this paper is to emphasise the benefits of establishing a communication channel between teachers and learners in the IWB technology classroom. Integrating ICT into the curriculum involves many challenges to both teachers and learners, who need to find their own ways to adapt to the new technology, understand its role in the pedagogical process, acquire new skills, and possibly change their social interactions and their ways of teaching and learning. Therefore, this dialogue between teachers and learners becomes even more essential, especially if both have the aim of using the technology to transform the language classroom and not only replicate old methods. The data analysis has shown that the channel of communication that was established between teacher and learners in this research was vital for an understanding of how the pedagogical practices and processes were being affected by the technology (while the technology was being taken up and reconstructed by the group), and for creating possible solutions for the challenges encountered.

\section{Notes}

1. The ACTIVslate is an A5 graphic tablet which operates remotely with the ACTIVboard enabling teachers and students to take control of the IWB from anywhere in the class.

2. The ACTIVote is a voting keypad enabling students to respond to assessment and other questions, which then can be analysed and presented rapidly by the ACTIVstudio software.

3. This approach means that a great deal of the class time is spent conducting practical exercises in which the students have the opportunity to use the ACTIVboard and remote devices to take part in class activities and carry out tasks.

4. The pedagogical zones referred here are the ones mentioned in the previous paragraph; that is, whole class interaction; collaborative learning; and a hands-on approach.

5. All names have been changed in order to protect students' anonymity.

6. The term anonymous mode is used to indicate that users will be asked to vote and then the results will be displayed after the vote, but the group will be unable to determine who voted for what 
answer. The term named mode is used to indicate that users will be asked to vote and then the results will be displayed and the group will be able to see each individual named alongside their vote.

\section{Notes on contributor}

Euline Cutrim Schmid is a Junior Professor at the University of Education (Pädagogische Hochschule) Heidelberg in Germany. She has a Ph.D. in Linguistics from Lancaster University, UK. Her doctoral research, concluded in November 2005, focused on the use of interactive whiteboard technology for the teaching of English as a Foreign Language (EFL). From 2003 to 2005 she worked as a part-time tutor at Lancaster University, where she taught applied linguistics and English for Academic Purposes (EAP) at undergraduate and postgraduate levels. She has an M.A. in Language Teaching from Lancaster University and an M.A. in Applied Linguistics from the Federal University of Rio de Janeiro, Brazil. Before teaching in the higher education context, she taught EFL for more than 10 years in various language schools in Brazil.

\section{References}

Bell, M. A. (2000). Impact of the electronic interactive whiteboard on students' attitudes and achievement in eighth-grade writing instruction. Unpublished $\mathrm{PhD}$ dissertation, Baylor University.

Bruce, B. C. (1997). Literacy technologies: what Stance should we take? Reading Online, 29(2), $289-309$.

Burden, K. (2002). Learning from the bottom up the contribution of school based practice and research in the effective use of interactive whiteboards for the FE/HE sector. Learning and skills research. Paper presented at the Making an Impact Regionally Conference, The Earth Centre, Doncaster.

Chapelle, C. (2003). English language learning and technology: lectures on applied linguistics in the age of information and communication technology. Amsterdam: John Benjamins.

Debski, R. (2003). Analysis of research in CALL (1980-2000) with a reflection on CALL as an academic discipline. ReCALL, 15(2), $177-188$.

Edwards, D., \& Mercer, N. (1987). Common knowledge: the development of understanding in the classroom. London: Methuen.

Erickson, F. (1986). Qualitative methods in research on teaching. In M. C. Wittrock (Ed.), Handbook of research on teaching. New York: Collier-Macmillan.

Feenberg, A. (1991). Critical theory of technology. New York: Oxford University Press.

Garrett, N. (1998). Where do research and practice meet? Developing a discipline. ReCall, 10(1), $7-12$.

Glover, D., \& Miller, D. (2001). Running with technology: the pedagogic impact of the large-scale introduction of interactive whiteboards in one secondary school. Fournal of Information Technologies for Teacher Education, 10(3), 257-278.

Goodison, T. (2003). Integrating ICT in the classroom: a case study of two contrasting lessons. British fournal of Educational Technology, 34(5), 549-566.

Greiffenhagen, C. (2000). From traditional blackboards to interactive whiteboards: a pilot study to inform technology design. Proceedings of the 24th International Conference Psychology of Mathematics Education, 24(2), 305-312. 
Levy, P. (2002). Interactive whiteboards in learning and teaching in two Sheffield schools: a developmental study. Retrieved December 5, 2002, from http://dis.shef.ac.uk/eirg/projects/ wboards.htm

Motteram, G. (1999). Changing the research paradigm: qualitative research methodology and the CALL classroom. In R. Debski, \& M. Levy (Eds.), WORLDCALL: global perspectives on computer-assisted language learning. Lisse: Swets \& Zeitlinger.

Shamim, F. (1996). Learner resistance to innovation in classroom methodology. In H. Coleman (Ed.), Society and the language classroom. Cambridge: Cambridge University Press.

Walker, R. (2003). Interactive whiteboards in the MFL classroom. TELL E CALL, 3(3), 14-16. Retrieved July 12, 2005, from http://www.e-lisa.at/magazine/tellcall/03_03.asp

Warschauer, M. (1998). Researching technology in TESOL: determinist, instrumental and critical approaches. TESOL Quarterly, 32(4), 757-761.

Warschauer, M. (1999). Electronic literacies: language, culture, and power in online education. Mahwah: Lawrence Erlbaum.

Warschauer, M. (2003). The allures and illusions of modernity: technology and educational reform in Egypt. Education Policy Analysis Archives, 11(38), 1-25.

Warschauer, M. \& Healey, D. (1998). Computers and language learning: an overview. Language Teaching, 31, 57-71. 